Open Access

\title{
Learning strategies and styles as a basis for building personal learning environments
}

Blanca J. Parra

\author{
Correspondence: \\ blancajanneth@gmail.com \\ Panamerican University Foundation, \\ Fundación Universitaria \\ Panamericana, 13250143 F Suba, \\ 111311 Bogotá, Colombia
}

\begin{abstract}
This paper presents the results and reflections from a study conducted on students using the e-learning mode from the Panamerican University Foundation. The aim of the study was to identify learning strategies and styles as a basis for building personal learning environments (PLEs). This study was conducted under the parameters of a mixed research approach, which uses quantitative and qualitative techniques, as well as an interpretative approach. The main learning styles found were active, visual and global. In relation to learning strategies, a tendency towards web searching as well as schemes and summary preparation was found. Although these are the prevailing trends, the study allowed us to recognize that each person learns differently; their style and learning strategies are influenced by the environment and the resources at their disposal. This enables educational institutions to identify and make a available the techno-pedagogical tools and strategies required to strengthen and build PLEs that are more assertive and better adapted to the needs and interests of students.
\end{abstract}

Keywords: Styles, Strategies, Learning, Environments, E learning

\section{Introduction}

Education, over time and through the challenges of society, has undergone several transformations in educational communities, giving rise to the need to propose new strategies and resources that promote, encourage and strengthen learning, making it a meaningful and enriching experience for the various stakeholders in the process (Carrillo et al. 2012). When asked about new educational proposals, we are faced with a number of possibilities, ranging from traditional teacher-centered approaches to student-centered approaches; in the case of the latter, the student plays a fully participatory role and control stance, not only in the process but also in the selection of content and activities, as suggested by Coomey and Stephenson (cited by Casamayor et al., 2008) on the grid of elearning educational models.

Among the different concepts that have gained strength in recent years is the personal learning environment (PLE), which refers to innovative spaces that encourage the generation of knowledge through the integration of different elements, both pedagogical and technological, and allow students to take control of their learning process so that they can set their own goals, manage their work and communicate with others.

Cabero et al. (2011) suggest, with regard to the origins of PLE, that there are two approaches, a pedagogical one and a technological one. The pedagogical one is understood as a change in educational methodology that promotes self-learning through the

(c) 2016 Parra. Open Access This article is distributed under the terms of the Creative Commons Attribution 4.0 International License (http://creativecommons.org/licenses/by/4.0/), which permits unrestricted use, distribution, and reproduction in any medium, provided you give appropriate credit to the original author(s) and the source, provide a link to the Creative Commons license, and indicate if changes were made. 
use of resources available on the network. It is a system that focuses on the student and allows him/her to take control of his/her learning process to set his/her own goals, manage his/her activity process and communicate with others.

The technological approach refers to the PLE as a software application comprising a repository of content and different management and communication tools.

Meanwhile, Adell and Castañeda (2010) do not directly relate PLEs to technological resources, and indicate that all types of variables are involved in them (home, school and friends, among others), because the processes of learning achieved in groups and in interaction with others. Ron Lubenskyv says that PLEs have a facility for individuals to access, add, configure and manipulate digital artifacts or tools for continuous learning experiences (cited by Santamaría 2010).

However, PLE implementation is not always achieved successfully by culture and traditional methods of teaching and learning in the formative stage: institutions provide resources and implement, in some cases, innovative teaching strategies for learning, but to what extent do they respond to the needs and learning styles of the students?

This study has been designed to answer this question; it takes into account the different learning styles and strategies for effective PLE construction.

\section{Problem statement}

A constant concern of tutors, consultants and, in general, educational institutions offering education in e-learning mode is related to how students acquire, analyze and share knowledge. Many of the resources provided in virtual learning platforms are not adjusted to the needs and learning styles of each person, and the potential of resources is not taken advantage of to build PLEs.

On the other hand, students are unaware of their learning styles and the effectiveness of the strategies used in the education process.

Hence the need arises to implement strategies and resources aimed at strengthening the teaching-learning process, enabling students to enhance their skills and abilities by identifying their learning strategies and styles. This is the key focus of this research, based on the following question:

How can students' learning strategies and styles, in e-learning mode, be identified so that they can contribute to the assertive construction of their PLEs?

\section{Justification}

One of the challenges of education in Colombia, listed in the Ten-Year Education Plan 2006-2016, is to ensure access to, and use and critical appropriation of information and communication technologies (ICTs) as tools for learning, creativity, and scientific, technological and cultural progress, such that it allows for human development and active participation in the knowledge society. There is also a need to promote curricular renovation of school levels and the basic functions of education and research and innovation, and to establish content and assessment practices that encourage learning and the social construction of knowledge according to the stages of development, expectations and individual and collective needs of students within their context and the world today (Ministerio de Educación Nacional de Colombia 2006). 
At this stage and in order to contribute to the education plan, it is important for educational institutions to have the resources and didactic tools required to enable students to identify and enhance their learning styles and strategies, providing educational materials that respond to their needs and encourage their active participation. In this way, we can contribute to a genuine process of personalized and student-centered learning, under the premise that every individual learns and constructs knowledge differently based on their cognitive abilities, interests and preconceptions, hence the importance of promoting active, dynamic and collaborative learning, sharing experiences and generating new knowledge, supported by the use of ICTs. This will be possible if educational institutions have techno-pedagogical resources and strategies adapted to the learning styles of each student, and through the identification of these, more assertive PLEs can be built that are tailored to their needs and interests.

The outcomes of this research are instruments that can be applied to students using the e-learning mode in order to perform continuous monitoring to identify students' learning styles and develop strategies ranging from the very process of mentoring to the development and availability of resources on the platform.

Aim

The aim of this study is to identify the learning strategies and styles of students using the e-learning mode as a basis for building PLEs. To that end, the following objectives have been set:

- To recognize those elements that affects the construction of a PLE.

- To conduct an analysis of the studies and techniques in order to identify the learning strategies and styles of students in different learning contexts.

- To determine techniques and adapt instruments in order to identify the learning strategies and styles of students using the e-learning mode.

\section{Method}

This study was conducted under the parameters of a mixed research approach, which uses quantitative and qualitative techniques, as well as an interpretive approach. Hernández et al. (2010) states that joint investigations refer to a process of collecting, analyzing and linking quantitative and qualitative data in a single study or a series of investigations to answer a research question. This type of research allows the object of study to be analyzed in its natural context, from the point of view of the participants as they perceive it. On the other hand, the use of the interpretive approach involves the description and analysis of learning styles and strategies based on the attitudes, behavior, cognitive features, and the emotional, physiological and procedural characteristics of students using the elearning mode (Rodríguez \& Valldeoriola 2009).

\section{Population}

The study was conducted with undergraduate students from the Panamerican University Foundation (Unipanamericana), who were taking their course of studies in e-learning mode. In the second half of 2013, during which the research instruments were applied, 
there were 285 students enrolled on the various programs offered by Unipanamericana in e-learning mode.

\section{Sample}

A non-probabilistic sample was used for this study. Questionnaires were sent to all students using the e-learning mode and 54 participated in the study, corresponding to $19 \%$ of total students enrolled. Tables 1 and 2 below detail the universe and the corresponding sample:

\section{Research techniques}

A combination of techniques allowed us to collect the necessary data to answer the research question, such as the survey, in-depth interviews and a literature review.

The survey technique was conducted via online resources, where an electronic questionnaire was used to collect structured data through closed dichotomous questions, multiple choice questions and others with alternative ordinate answers of the Likert type. The latter were used to identify the students' learning strategies.

The survey aimed to identify the learning strategies and styles of students using the e-learning mode at Unipanamericana.

The interviews allowed the respondents' ideas, beliefs and assumptions (Meneses \& Rodríguez 2011) of learning strategies used and their impact on the learning process to be approached and understood.

The purpose of the interview was to understand the students' conceptions of learning strategies and to identify the strategies they use and their impact on the learning process.

The interview was semi-structured since it was conducted from a script that allowed the interviewer to prepare information and familiarize him/herself with the topic being investigated. The central questions were open, which encouraged the interviewee to express flexible and comprehensive answers.

The literature review involved finding research and articles related to the learning strategies and styles of students in different learning contexts. The search was performed in specialized databases using search criteria to filter the most relevant and recent research publications.

Table 1 Population of e-learning students at Unipanamericana

\begin{tabular}{|c|c|c|c|c|c|c|}
\hline \multirow[t]{3}{*}{ Program } & \multicolumn{6}{|c|}{ Universe } \\
\hline & \multicolumn{2}{|l|}{$\overline{M e n}$} & \multicolumn{2}{|c|}{ Women } & \multirow[t]{2}{*}{ Total enrolled } & \multirow[t]{2}{*}{$\%$ program } \\
\hline & $\overline{\text { No }}$ & $\%$ & No & $\%$ & & \\
\hline Systems Engineer & 35 & $85 \%$ & 6 & $15 \%$ & 41 & $14 \%$ \\
\hline Telecommunications Engineering & 34 & $94 \%$ & 2 & $6 \%$ & 36 & $13 \%$ \\
\hline Marketing and Advertising & 24 & $42 \%$ & 33 & $58 \%$ & 57 & $20 \%$ \\
\hline Business Administration & 25 & $34 \%$ & 48 & $66 \%$ & 73 & $26 \%$ \\
\hline Visual Design & 30 & $62 \%$ & 18 & $38 \%$ & 48 & $17 \%$ \\
\hline \multirow[t]{2}{*}{ Finance and International Business } & 10 & $33 \%$ & 20 & $67 \%$ & 30 & $11 \%$ \\
\hline & 158 & $55 \%$ & 127 & $45 \%$ & Totalenrolled: 285 & \\
\hline
\end{tabular}


Table 2 Sample of students on whom the survey was conducted

\begin{tabular}{|c|c|c|c|c|c|}
\hline \multicolumn{6}{|c|}{ Sample } \\
\hline \multicolumn{2}{|c|}{ Men } & \multicolumn{2}{|c|}{ Women } & \multirow{2}{*}{$\begin{array}{l}\text { Total enrolled per } \\
\text { program }\end{array}$} & \multirow{2}{*}{$\begin{array}{l}\% \text { program } \\
\text { participants }\end{array}$} \\
\hline No. & $\%$ & No. & $\%$ & & \\
\hline 6 & $17 \%$ & 2 & $33 \%$ & 8 & $20 \%$ \\
\hline 6 & $18 \%$ & 0 & $0 \%$ & 6 & $17 \%$ \\
\hline 4 & $17 \%$ & 9 & $27 \%$ & 13 & $23 \%$ \\
\hline 4 & $16 \%$ & 9 & $19 \%$ & 13 & $18 \%$ \\
\hline 4 & $13 \%$ & 5 & $28 \%$ & 9 & $19 \%$ \\
\hline 2 & $20 \%$ & 3 & $15 \%$ & 5 & $17 \%$ \\
\hline 26 & $17 \%$ & 28 & $20 \%$ & 54 & $19 \%$ \\
\hline
\end{tabular}

\section{Types of research tool}

As an instrument of the survey technique, a questionnaire was used. This was constructed on the basis of a literature review of studies and techniques that helped to identify the learning strategies and styles of students in different learning contexts. The CHAEA tests were analyzed; CHAEA tests are the Spanish version of the LSQ tool proposed by Honey and Mumford (1988, cited by Alonso, \& Gallego, 2006)) and the Index of Learning Styles Questionnaire by Felder and Soloman (2008). Likewise, the CEVEAPEU questionnaire was analyzed, which is used to assess the learning strategies of university students (Gargallo et al. 2009). A process of selection, classification and adaptation of the questions was conducted and new questions were asked; all of these focused on the aim of this study.

For the interview technique, a script was made to allow the researchers to direct their questions according to the study aim and variables. In addition to the script there was a protocol giving the interviewer general guidelines to consider before, during and after the interview.

The script consisted of 18 questions, of which 6 were closed and corresponded to the respondents' general information, and a section intended for respondents to give their consent to participating in the process of data gathering and dissemination within the framework of this study. There were also 12 open questions focusing on learning strategies. Thus the relationship of the study objectives to the research question was evident. Finally, a section was assigned to the interviewer to assess the interview. Some of the issues presented in the script are based on scripts validated and implemented in other research: the development of an oral source (Pantaleón \& Rey 2006) and the design of a system for the management and control of the production of content and learning objects, for e-learning at Unipanamericana (Parra, 2010).

On the other hand, the data obtained from the literature review were listed in a matrix outlining the most important aspects of selected publications (general topic or title of the project consulted, authors, year, country, educational institution and funding body, specialist database, URL data, document type, search criteria used, keywords, synthesis and contribution), thus allowing their objects of study to be contextualized, their status to be identified, their results compared and the respective document analysis to be performed. 


\section{Fieldwork}

Data gathering was conducted electronically as follows:

1) The questionnaire was made available on Google Drive and sent to students via the institution's e-mail system. It was addressed to all students and was notified through different electronic media.

2) For the interviews, three students were selected from the active programs in e-learning mode at Unipanamericana, who voluntarily chose to participate in it. The interviews were conducted individually via Skype, following protocol and script, designed for the application of the instrument, where the interviewer created a bond of trust with the interviewees and thus achieved an in-depth interview.

\section{Results}

\section{Learning styles of students using the e-learning mode at Unipanamericana}

Table 3 shows the predominant learning styles of the 54 students surveyed, defined from the model of learning styles by Felder and Silverman:

Following Felder and Silverman's bipolar category, in Category 1, the active learning style predominated (89\% of the students surveyed), according to the Index of Learning Styles Questionnaire (Felder \& Soloman, 2008.); the students in whom this style predominates tend to retain and understand information dynamically through dialogues or by explaining to others, and they are generally more likely to work in groups. For their part, reflective students tend to think about and process information in silence before giving their point of view and generally prefer individual work. Of the respondents, $9 \%$ can be found in this category, and $2 \%$ in both learning styles.

In category 2 , the intuitive style predominated ( $44 \%$ of the students surveyed), while only $15 \%$ of the respondents can be found in the sensitive style. However, the prevalence of both learning styles is evident ( $41 \%$ of the students surveyed). Sensitive students tend towards fact-based learning through problem solving and memorization of situations via laboratories and workshops, whereas intuitive students are often interested in discovery,

Table 3 Predominant learning styles of e-learning students at Unipanamericana

\begin{tabular}{|c|c|c|c|}
\hline & \multicolumn{3}{|c|}{ Learning styles predominant in the sample } \\
\hline & Learning styles & Number of students & Media \\
\hline \multirow[t]{3}{*}{ Category 1} & Active & 48 & $89 \%$ \\
\hline & Reflective & 5 & $9 \%$ \\
\hline & Active/Reflective & 1 & $2 \%$ \\
\hline \multirow[t]{3}{*}{ Category 2} & Sensitive & 8 & $15 \%$ \\
\hline & Intuitive & 24 & $44 \%$ \\
\hline & Sensitive/Intuitive & 22 & $41 \%$ \\
\hline \multirow[t]{3}{*}{ Category 3} & Visual & 45 & $83 \%$ \\
\hline & Verbal & 4 & $7 \%$ \\
\hline & Visual/Nerbal & 5 & $9 \%$ \\
\hline \multirow[t]{2}{*}{ Category 4} & Sequential & 7 & $13 \%$ \\
\hline & Global & 47 & $87 \%$ \\
\hline
\end{tabular}


exploration and connections, are innovative and often have a flair for abstraction and mathematical operations.

In category 3 , the visual learning style predominated ( $83 \%$ of the students surveyed), that is, they are students who better remember what they see (pictures, graphs, charts, timelines, videos and flow charts, among others), while only $7 \%$ of the respondents can be found in the verbal style. Verbal students generally tend to learn best through lectures, readings, discussions and other spoken or written expressions. However, the prevalence of both learning styles is $9 \%$. This implies that, in $92 \%$ of the sample, the visual style predominates, something that is favored in e-learning since it has several educational resources and graphic materials.

Finally, in category 4 , the predominance of the global style is evident ( $87 \%$ of the students surveyed); they are students who tend to learn in blocks without connections, are often able to solve complex problems quickly, but may struggle to explain how they do so. Of the respondents, $13 \%$ can be found in the sequential style. The latter style is characterized by linear learning, following logical steps in search of solutions to problems, and through connections. Among the students surveyed, the global and sequential styles were not found to exist equitably.

In relation to the gender variable, and according to the results presented in Table 4, the predominant learning style among women is global with $86 \%$, followed by the visual and active with $79 \%$ each. Meanwhile, among men, the predominant learning style is active with $100 \%$, followed by visual and global with $88 \%$ each. This indicates that there is a higher prevalence for the same learning styles in both genders.

\section{Learning strategies of students using the e-learning mode}

The interview data were categorized retaining the classification of learning strategies (Gargallo et al. 2009) and, from these, the following scheme was generated: (Fig. 1).

Respondents expressed their interest in individual work; it allows them to optimize time because of the technical and timing difficulties involved in synchronous meetings. However, in group work they are characterized as leaders and active. Among the

Table 4 Predominant learning styles of e-learning students at Unipanamericana, categorized by gender

\begin{tabular}{|c|c|c|c|c|c|}
\hline \multirow[b]{3}{*}{ Category 1} & \multicolumn{5}{|c|}{ Predominant learning styles in the sample, by gender } \\
\hline & \multirow{2}{*}{$\begin{array}{l}\text { Learning styles } \\
\text { Active }\end{array}$} & \multicolumn{2}{|c|}{ Female } & \multicolumn{2}{|c|}{ Male } \\
\hline & & 22 & $79 \%$ & 26 & $100 \%$ \\
\hline & Reflective & 5 & $18 \%$ & 0 & $0 \%$ \\
\hline & Active/Reflective & 1 & $4 \%$ & 0 & $0 \%$ \\
\hline \multirow[t]{3}{*}{ Category 2} & Sensitive & 6 & $21 \%$ & 2 & $8 \%$ \\
\hline & Intuitive & 12 & $43 \%$ & 12 & $46 \%$ \\
\hline & Sensitive/Intuitive & 10 & $36 \%$ & 12 & $46 \%$ \\
\hline \multirow[t]{3}{*}{ Category 3} & Visual & 22 & $79 \%$ & 23 & $88 \%$ \\
\hline & Verbal & 3 & $11 \%$ & 1 & $4 \%$ \\
\hline & Visual/Verbal & 3 & $11 \%$ & 2 & $8 \%$ \\
\hline \multirow[t]{2}{*}{ Category 4} & Sequential & 4 & $14 \%$ & 3 & $0 \%$ \\
\hline & Global & 24 & $86 \%$ & 23 & $88 \%$ \\
\hline
\end{tabular}




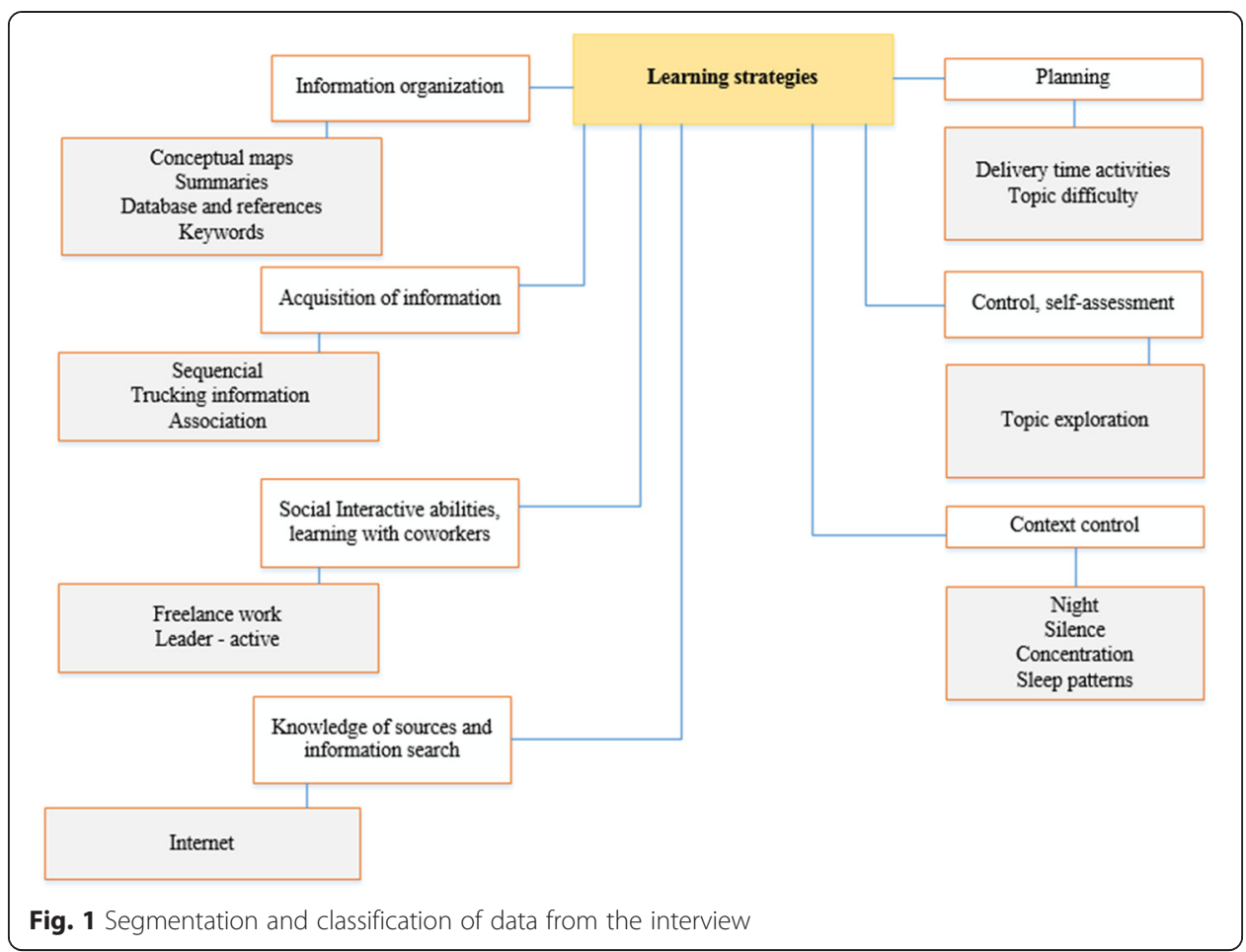

strategies for organizing information, the most commonly used are the development of conceptual maps, summaries, keywords and data banks. A technique used to optimize learning is the association of terms. In addition, those interviewed agreed that they are methodical and linearly follow instructions when undertaking an activity.

When they have doubts about a topic, the respondents stated that they initially turn to Internet sources and only turn to teachers when they require clarification of the instructions to undertake academic activities. As for the work environment, there is a preference for spaces of silence and tranquility at night-time, something that coincides with the data collected in the survey.

Undertaking activities is planned according to deadlines for delivery and the level of difficulty of the issues, giving priority to subjects of greater complexity. After receiving feedback from the teacher, the respondents said that they did not always explore the topic further unless, that is, the feedback was not clear or sufficiently detailed.

Finally, the respondents said that the role of the teacher was very important in terms of facilitating their education process.

\section{Discussion}

This study identified the learning strategies and styles of students using the e-learning mode at Unipanamericana, which showed that the active, visual and global styles predominant.

One thing to consider when learning environments and educational resources involved in PLEs are provided - which is significant in the sample - is that students prefer an environment isolated from noise and distraction factors, so as to enable better concentration and enhanced learning. For this reason, it is important to consider these conditions at the time of designing and publishing educational resources on virtual platforms, seeking 
balance between the different resources and ensuring that they are not distracting from the true purpose of learning that the students hope to achieve.

As for learning strategies, the trend among students is to make enquiries and address their concerns through various online resources. Faced with this situation, they have various options: to improve the quality and ultimately the accuracy of the information published on the network, though this does not depend solely on the teachers and students at Unipanamericana: while it is a viable alternative, it is insufficient. In short, we still need to generate the culture for students to seek out and identify reliable sources like books, specialist databases, scientific articles published in indexed journals, both nationally and internationally, and, finally to promote respect for copyright and the use of standards such as those of the American Psychological Association (APA).

Among the learning strategies, worthy of note is the fact that the students have a structure and are organized to carry out their learning process, plan their activities and to devote extra time to study. As for self-regulation, when undertaking their activities, the students realize whether or not they have been done properly, that is, they independently reflect on their own learning. However, it is necessary to continue strengthening the selfassessment strategies currently implemented at the university.

This indicates that is necessary to recognize that every individual learns and constructs knowledge differently based on their cognitive abilities, interests and preconceptions. This implies that knowledge is unique to the individual and depends on the pace of learning and the meaning given to it. Hence the importance of shifting towards active, dynamic and collaborative learning, sharing experiences and generating new knowledge, supported by the use of ICTs. This is possible if educational institutions have techno-pedagogical resources and strategies that are tailored to the learning styles of each student, and identifying them will allow them to build more assertive learning environments that are better tailored to their needs and interests. It is also important to create action plans that allow educational resources, platforms and mentoring processes to be adapted to the learning strategies and styles of students using the e-learning mode. Of particular importance within these plans is the implementation of instruments at different stages of the students' formative processes, report results available online to students and tutors, specialized study skills clubs from the predominant learning styles, time management resources and strategies, and the adaptation of resources to different formats for different devices, among others.

Finally, this study allowed a literature review to be conducted, which helped to determine the current status of the issue within the national and international context, and instruments to be made available to students using the e-learning mode at Unipanamericana to identify their learning styles and strategies, which are the cornerstones for building their PLEs.

\section{Study limitations and prospects}

During the course of the study, the greatest difficulty was encountered in the questionnaire implementation stage due to the timing of the academic recess for students in Colombia, which coincided with the data collection date. In the questionnaire implementation stage of future projects, it will be important to contact participants via email, social networks and institutional platforms to provide them with a preliminary summary of the study in order to encourage them to become part of the sample. 
Based on the results of this study, a new project has been started. The new project seeks to design software to allow students to undertake activities, each designed according to the questions of the instruments used during the study. By using the software, the students will be able to undertake these activities and, on completion, the software will tell each student what his/her dominant learning style is and suggest a series of learning strategies.

Likewise, the need arises to perform new studies to delve into the role of the tutor in the students' PLEs and learning styles, and into how the tutor will be able to guide the students to ensure that they are better used.

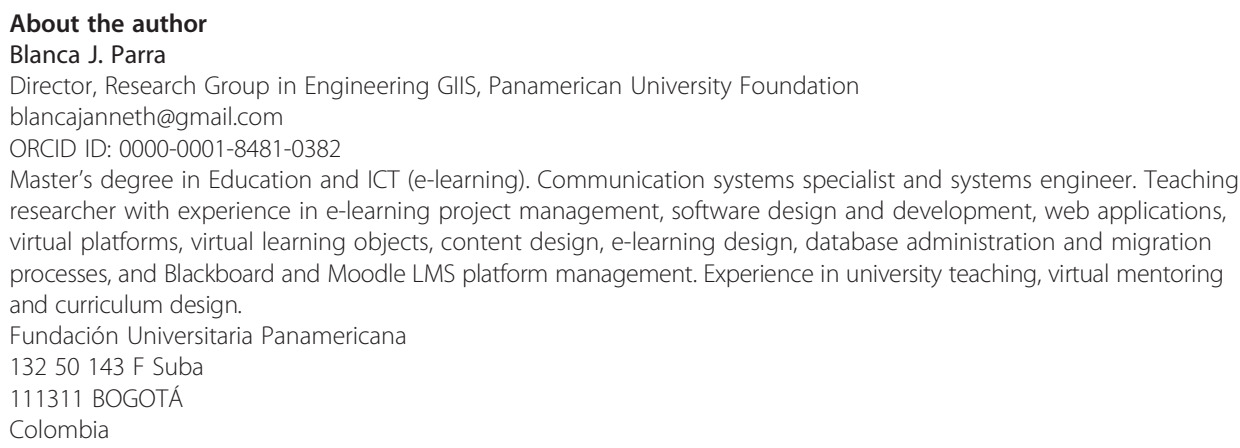

\section{References}

Adell J, Castañeda L (2010). Los Entornos Personales de Aprendizaje (PLEs): una nueva manera de entender el aprendizaje [Personal Enviroments of Learning, a new way to understand the learning process]. Spain. 7. Retrieved from http://digitum.um.es/xmlui/bitstream/10201/17247/1/Adell\&Casta\%C3\%B1eda_2010.pdf

Alonso C, Gallego D (2006). Estilos de aprendizaje. Cuestionario Honey-Alonso de Estilos de Aprendizaje. [Learning styles. Honey-Alonso Questionnaire Learning Styles]. Retrieved from http://www.estilosdeaprendizaje.es/

Cabero J, Marín V, Infante A (2011). Creación de un entorno personal para el aprendizaje: Desarrollo de una experiencia [Creating a personal environment for learning: Development of an experience.] Electronic journal of Educational Technology. Number 38. 4. Retrieved from http://edutec.rediris.es/Revelec2/Revelec38/pdf/Edutec-e_38_Cabero_ Marin_Infante.pdf

Carrillo V, Hernández A, Parra B, Pérez Y, Portilla D (2012). Elementos tecno-pedagógicos para la construcción efectiva de entornos personalizados de aprendizaje. Fase I. Grupo de Investigación en Educación Digital y Virtual. [Technopedagogical construction for effective personalized learning environments. Elements Phase I. Research Group Digital and Virtual Education]. (Undergraduate thesis). Panamericana University Foundation.

Casamayor G, Alós M, Chiné M, Dalmau O, Herrero O, Mas G, Pérez F, Riera C, Rubio A (2008). La formación On-line. Una mirada integral sobre el e-learning, b-learnin... The On-line training. A comprehensive look at the e-learning, b -learning.... . 82. Retrieved from http://books.google.com.co/books?ei=3Fh0T4CEElHe0QGtysj_Ag\&hl=es\&id= v1uOpG0a6T4C\&dq=Coomey+y+Stephenson+cuadricula+modelos\&ots=Gshldelvn0\&q=cuadrante\#v=snippet\&q= cuadrante\&f=false.

Felder R, Soloman B (2008). Learning styles and strategies. North Carolina State University. Retrieved from http://www4 ncsu.edu/unity/lockers/users/f/felder/public/ILSdir/styles.htm

Gargallo B, Suárez J, Pérez C (2009). El cuestionario CEVEAPEU. Un instrumento para la evaluación de las estrategias de aprendizaje de los estudiantes universitarios [An instrument for the assessment of the learning strategies of university students]. Retrieved from http://www.uv.es/RELIEVE/v15n2/RELIEVEv15n2_5.htm

Hernández S, Fernández C, Baptista M (2010) Metodología de la investigación [Research methodology]. Editorial McGraw Hill, Mexico, p 370

Meneses J, Rodríguez D (2011). El cuestionario y la entrevista [The questionnaire and interview]. Universitat Oberta de Catalunya. 36, 38

Ministerio de Educación Nacional de Colombia. MEN. Plan Decenal de Educación 2006-2016 [Ten- Year Education Plan 2006-2016]. 17, 21. Retrieved from http://www.plandecenal.edu.co/html/1726/articles-166057_cartilla.pdf.

Pantaleón C, Rey T (2006). Elaboración de una fuente oral. USC [Development of an oral source] Retrieved from http://webspersoais.usc.es/export/sites/default/persoais/eduardo.rey/descargas/Guion_para_la_preparacion_de_ la_entrevista.pdf

Parra V (2010). Diseño del sistema para la gestión y control de la producción de contenidos y objetos de aprendizaje, para la formación virtual en la Fundación Universitaria Panamericana [Design of the system for management and 
control of the production of content and learning objects, for virtual training]. (Undergraduate thesis). Panamericana University Foundation, Colombia

Rodríguez G, Valldeoriola R (2009). Metodología de la investigación. (Reseach Methodology) Universitat Oberta de Catalunya. 53. Retrieved from http://zanadoria.com/syllabi/m1019/mat_cast-nodef/PID_00148556-1.pdf

Santamaría F (2010). Entornos personales de aprendizaje: una propuesta tecnológico-educativa para la integración en el aula. Retos Educativos en la Sociedad del Conocimiento. [Personal learning environments: a technological educational proposal for integration in the classroom. Educational Challenges in the Knowledge Society]. Barcelona. 2. Retrieved from http://fernandosantamaria.com/blog/docs/retos_educativos_sociedad_conocimiento_ santamaria.pdf

Submit your manuscript to a SpringerOpen ${ }^{\circ}$ journal and benefit from:

- Convenient online submission

- Rigorous peer review

- Immediate publication on acceptance

Open access: articles freely available online

- High visibility within the field

- Retaining the copyright to your article

Submit your next manuscript at $>$ springeropen.com 